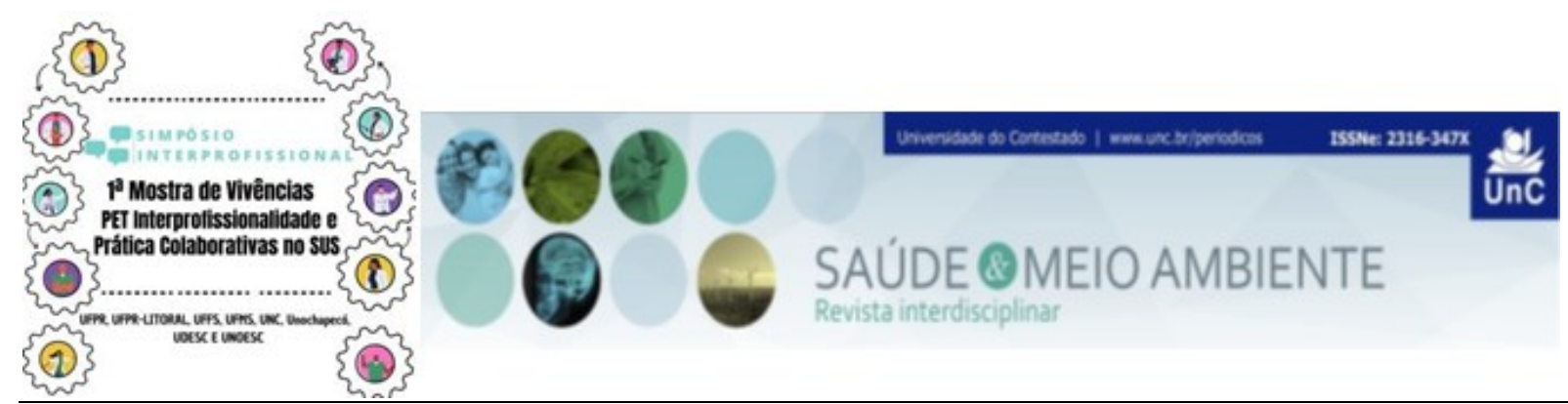

\title{
DESENVOLVIMENTO E UTILIZAÇÃO DE RECURSOS EDUCACIONAIS ABERTOS NO GRUPO PET SAÚDE/INTERPROFISSIONALIDADE - REDES DE ATENÇÃO DA UFPR ${ }^{1}$
}

\author{
Projeto 88 \\ Marcel Pereira Gritten² \\ Liana Signorini ${ }^{3}$ \\ Maria Gabriela Rodrigues de Souza ${ }^{4}$ \\ Nicolle Boell Heiden ${ }^{5}$ \\ Leandra Rosa ${ }^{6}$ \\ Allan Kardec de Lima7 \\ Rafaela Gessner Lourenço ${ }^{8}$
}

\begin{abstract}
RESUMO
Introdução: Os Recursos Educacionais Abertos (REA) são definidos como materiais de ensino, pesquisa e extensão, publicados sob licença aberta ou em domínio público. Por isso, são caracterizados como um bem comum, com pouca ou nenhuma limitação de direito autoral. Visam promover a equidade na educação, tornando-a inclusiva e de qualidade, mediante colaboração e compartilhamento de conhecimento de forma gratuita1. Objetivo: relatar a experiência da criação de dois materiais educativos publicados como Recursos Educacionais Abertos no Repositório Digital da Universidade Federal do Paraná. Metodologia: trata-se de um relato de experiência de natureza descritiva. Resultados: Os REAs foram desenvolvidos nos meses de abril e junho de 2020 e orientados pelos princípios de colaboração e interatividade dos meios digitais. O primeiro REA, elaborado em formato de cartilha e intitulado "Manual de Tubos de Coleta de Sangue", foi criado como proposta de intervenção em um dos equipamentos de saúde do município de Curitiba em que se desenvolvem atividades de preceptoria do grupo PET Saúde/Interprofissionalidade - Rede de Atenção. Esse REA contempla os principais tubos de coleta de sangue utilizados na rotina
\end{abstract}

${ }^{1}$ Fonte de financiamento: Programa de Educação pelo Trabalho para a Saúde - PET

Saúde/Interprofissionalidade 2019-2021 (Edital no 10 de 23 de julho de 2018, Ministério da

Saúde/Secretaria de Gestão do Trabalho e da Educação na Saúde).

${ }^{2}$ Aluno bolsista. Universidade Federal do Paraná. Paraná. Brasil. E-mail: marcelgritten@gmail.com.

${ }^{3}$ Preceptora. Prefeitura Municipal de Curitiba. Paraná. Brasil. E-mail: lianasig@gmail.com.

${ }^{4}$ Aluna bolsista. Universidade Federal do Paraná. Paraná. Brasil. E-mail:

mariagabrielarsouza@gmail.com.

${ }_{5}^{5}$ Aluna bolsista. Universidade Federal do Paraná. Paraná. Brasil. E-mail: nicolleboell@gmail.com.

${ }^{6}$ Preceptora. Prefeitura Municipal de Curitiba. Paraná. Brasil. E-mail: sarolle@hotmail.com.

${ }^{7}$ Tutor. Docente do departamento de farmácia da Universidade Federal do Paraná. Paraná. Brasil. Email: lima.allan@gmail.com.

${ }^{8}$ Coordenadora de grupo tutorial. Docente do departamento de enfermagem da Universidade Federal do Paraná. Paraná. Brasil. E-mail: rglufpr@gmail.com 
ambulatorial, abordando a finalidade e importância de cada um, para garantir a viabilidade das amostras e a qualidade dos resultados laboratoriais. Esse material atingiu, até agosto de 2020, 161 visualizações, sendo $70 \%$ (112) delas de alcance internacional ${ }^{2}$. O segundo REA, em formato de cartilha, "Diagnóstico Laboratorial do Coronavírus (Sars-Cov-2) (agente etiológico da COVID-19)", mostra os princípios, vantagens e as principais diferenças entre os dois principais métodos laboratoriais utilizados para o diagnóstico da COVID-19: o teste molecular (RT-PCR em tempo real) e o teste sorológico (teste rápido). Com impacto semelhante, tal publicação obteve 179 visualizações, sendo a maioria delas $84 \%$ (150) realizadas em outros países ${ }^{3}$. Esse material objetiva oferecer suporte a acadêmicos, profissionais de saúde e à comunidade externa sobre temática relevante da atualidade. Considerações Finais: A utilização da modalidade de Educação Aberta apresenta vantagens como, o custo reduzido, promoção da ampliação do acesso à educação e o alcance global das publicações, conforme foi observado nos REA produzidos e disponibilizados pela equipe do PET Redes de Atenção da UFPR. Dessa forma, além de priorizar a difusão do conhecimento produzido em suas atividades, a equipe buscou novas maneiras de contribuir para o debate e intercâmbio entre diferentes teias da produção científica.

Palavras-chave: Educação Continuada. Educação Interprofissional. Materiais de Ensino.

\section{REFERÊNCIAS}

1. Zanin AA. Recursos educacionais abertos e direitos autorais. Ver. Bras. Educ. 2017; 22(71);1-25. Disponível em: http://doi.org/10.1590/s1413-24782017227174

2. Lourenço RG, Lima AK, Santos DVD, Alessi SM, Daniel E, Castro DF, et al. Manual de Tubos de Coleta de Sangue. Repositório Digit Inst da UFPR [Internet]. 2020; Disponível em: https://acervodigital.ufpr.br/handle/1884/66510

3. Lourenço RG, Lima AK, Santos DVD, Alessi SM, Daniel E, Castro DF, et al. DIAGNÓSTICO LABORATORIAL DO CORONAVÍRUS (SARS-CoV-2) (agente etiológico da COVID-19). Repositório Digit Inst da UFPR [Internet]. 2020; Disponível em: https://acervodigital.ufpr.br/handle/1884/66983 